\section{THE UNSENSORED VERSION}

Biosensors: Applications in Medicine, Environmental Protection and Process Control. R.D.

Schmid \& F. Scheller, eds. ISBN 0-89573-955-0. DM128.00 (VCH Publishers, Heidelberg: 1989).

Biosensors. Elizabeth A. H. Hall. ISBN 0-335-15894 $3 £ 50.00$ (cased) (Open University Press, Milton Keynes, U.K. 1990).

Biosensors: A Practical Approach. Edited by A.E.G. Cass. ISBN 0-19-963046-1 £30.00 (cased) (Oxford University Press, Oxford, U.K.: 1990).

$\mathbf{R}$

emember biosensors? In the heady days of the early eighties they were, according to their more enthusiastic proponents, poised to revolutionise analytical methods in a whole range of areas. And yet, ten years later, very few of us have ever even seen a biosensor let alone used one.

It is evident from the sheer number of recent scientific publications that the biosensor bandwagon is still well and truly rolling. Readers wishing to assess the current state of play in biosensor research would be well advised to start with a copy of the Open University Press' Biosensors. For those already in the area or with the facilities and inclination to build their own biosensors, Biosensors: A Practical Approach (Oxford University Press) may be a useful addition to their library. This is a do-it-yourself handbook of biosensor construction with detailed instructions on how to build a variety of working biosensors for a range of applications. Many promising prototype biosensors are also described in Biosensors: Applications in Medicine, Environmental Protection and Process Control, the proceedings of a 1989 workshop held under the auspices of GBF (Braunschweig, Germany). Among the most ambitious projects is a collaboration involving researchers at Dusseldorf, Frankfurt, and Halle which aims to develop home screening for phenylketonuria. Environmental sensors, too, abound: whole-cell sensors for biological oxygen demand and pesticide sensors based on acetylcholine esterase are just two examples.

Despite the existence of many biosensors of varying degrees of sophistication in research laboratories throughout the world, the transition to commercial reality has not occurred to any great degree. For instance, even though the food industry recognises that a hypoxanthine biosensor would be an ideal method of monitoring "freshness" in fish, only primitive designs have been developed. The main problem in this case (and in most others) is the robustness of the interface between the biology and the transducer. The solution may be to recognise that biosensors need nurturing within a collaborative and multidisplinary environment.

Given that environment, similar books ten years hence will probably be able to describe products rather that prototypes. The evidence to date suggests that many of those products will originate from Germany and Japan.

Pete Border, Ph. D. resides at 8 Lothian Crescent, Cyncoed, Cardiff CF3 $7 H Y, U . K$.

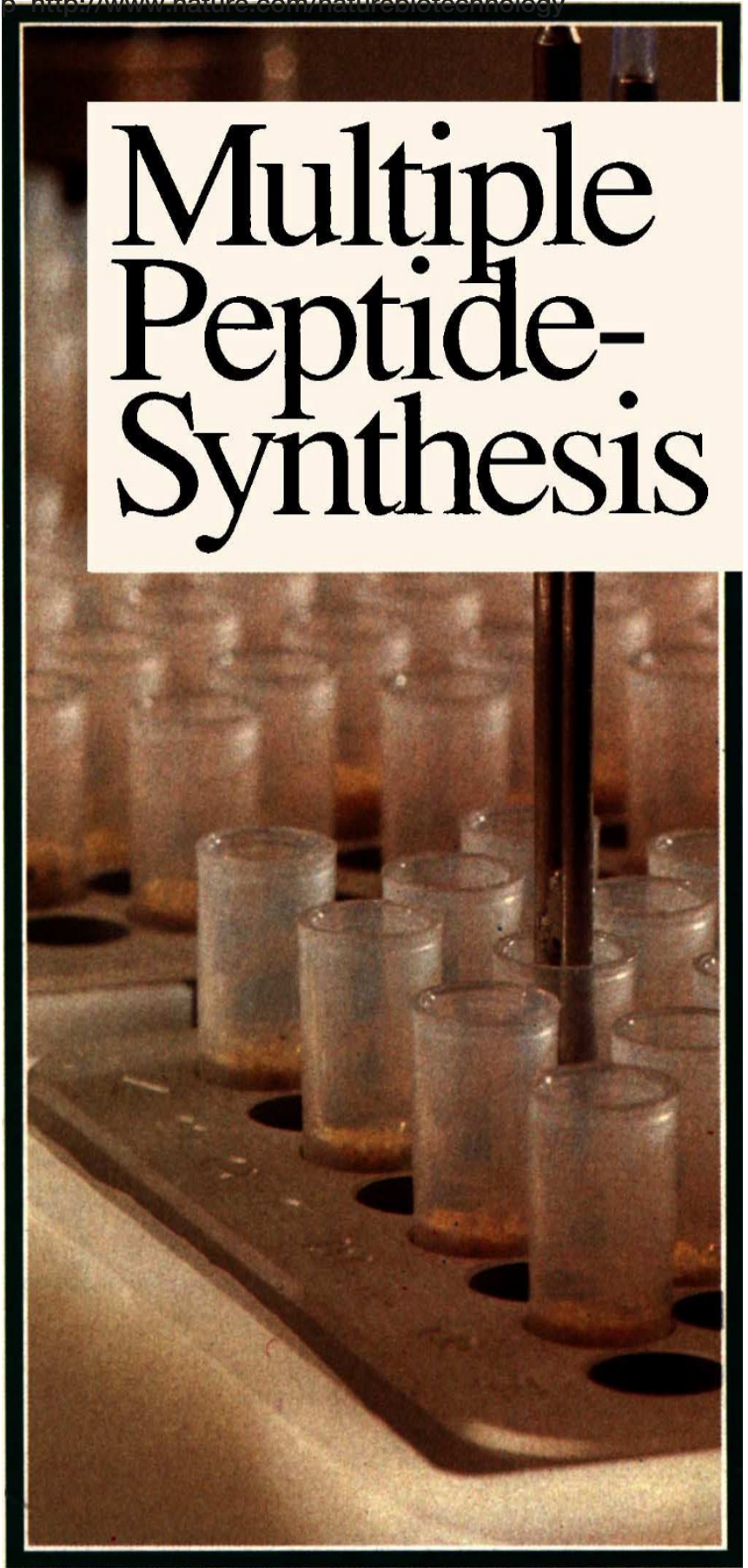

To meet the growing requirements for peptides for screening purposes ZINSSER ANALYTIC has developed the SMPS 350 for the faster Peptide Synthesis. This fully automated instrument can synthesize up to 144 peptides of various structures and lengths of sequences simultaneously with commercially available polystyrene resins in accordance with the Fmoc-strategy. Typical quantities used are 10 to $50 \mathrm{mg}$ of resins. The loading is unlimited.

A user-friendly program controls the synthesis process automatically via a personal computer. The operator merely determines the sequences of the peptides. The purity of the peptide is comparable with results

achieved with conventional

synthesizers. Frequently, the product is even purer.

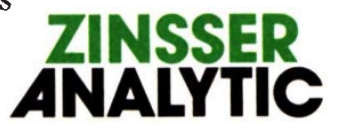

ZINSSER ANALYTIC GmbH, Eschbomer Landstraße 135, 6000 Frankfurt 94, Telefon (069)789106-0, Fax (069) 789106-80, Telex 414265 zins d - ZINSSER ANALYTIC Ges.m.b.H., ABmayergasse 60, 1120 Wien, Telefon 02228132172 , Fax 0222813217215 ZINSSER ANALYTIC (UK) Ltd., Howarth Road, Stafferton Way, Maidenhead Berks., SL6 1AP, Telephone 0628/773202, Fax 0628/72199. Advanced ChemTech, P.O.Box 1403, Louisville, Kentucky 40201, Telephone 502-636 0000, Fax 502-636 5604 